Article

\title{
Low Inertia Systems Frequency Variation Reduction with Fine-Tuned Smart Energy Controllers
}

\author{
Minas Patsalides*(D), Christina N. Papadimitriou and Venizelos Efthymiou \\ FOSS Research Centre for Sustainable Energy, University of Cyprus, 1678 Nicosia, Cyprus; \\ papadimitriou.n.christina@ucy.ac.cy (C.N.P.); efthymiou.venizelos@ucy.ac.cy (V.E.) \\ * Correspondence: patsalides.minas@ucy.ac.cy
}

check for

updates

Citation: Patsalides, M. Papadimitriou, C.N.; Efthymiou, V. Low Inertia Systems Frequency Variation Reduction with Fine-Tuned Smart Energy Controllers.

Sustainability 2021, 13, 2979.

https://doi.org/10.3390/su13052979

Received: 25 December 2020

Accepted: 1 March 2021

Published: 9 March 2021

Publisher's Note: MDPI stays neutral with regard to jurisdictional claims in published maps and institutional affiliations.

Copyright: (c) 2021 by the authors. Licensee MDPI, Basel, Switzerland. This article is an open access article distributed under the terms and conditions of the Creative Commons Attribution (CC BY) license (https:// creativecommons.org/licenses/by/ $4.0 /)$.

\begin{abstract}
The distributed and stochastic nature of Renewable Power Sources is certainly forming considerable challenges for the operation of the power system. Specifically, the stability of the system can be jeopardized when the penetration of inverter-based systems is high. Storage and the proper design of controllers is seen as part of the solution for supporting the future expansion of distributed systems. Thus, control strategies need to be designed to provide the appropriate support to the system and be capable of keeping the variation of the frequency within limits to keep the reliability of the system as high as possible. The main challenge is the appropriate parameterization of these distributed controllers and their coordination under the integrated grid approach in securing the stability of the system at all times. In this paper, a smart energy controller is utilized and incorporated into the projection case study for Cyprus' real distribution grid for the year 2050 to evaluate its behavior and identify possible weaknesses in its usage. It was found that the parameterization and not only the architecture of such controllers is crucial in coping with the frequency variation and stability problem. From the simulation work and recorded results, it was observed that the smart energy controllers can maintain frequency variation within the desirable range when the parametrization of the controllers is chosen appropriately. This specific observation highlights the need to evaluate and configure the smart controllers while operating in the field, and possibly further research is required to provide the advanced capability to such systems to adjust dynamically during field operation, thereby achieving better response during abnormal conditions.
\end{abstract}

Keywords: frequency variation; low inertia systems; distributed power resources; smart energy controllers; system stability; distribution grid

\section{Introduction}

\subsection{Problem Formulation}

Renewable energy sources (RES) are considered a valuable energy production technology solution targeted to benefit the environment by reducing greenhouse gas emissions. The distributed and volatile nature of RES, though, imposes great challenges to grid system operators, while performing the needed integration and management activities [1,2].

To handle these inherent problems, and to harvest huge amounts of renewable energy by successfully integrating low carbon technologies, supporting technologies, including means of storage, are required to facilitate security of supply throughout the day and year. Various research projects and studies are underway to define the best options, setup, mix of technologies and grid structure to cope with the mandatory and unavoidable reforming of the power grid, which will have the ability to host high penetrations of RES [3-6].

A fundamental problem caused by the usage of inverter-based, low-inertia RES systems is their inability to directly support system frequency during the occurrence of abnormal power events due to a lack of additional renewable energy resource. The "renewable" fuel cannot be increased in any way as is done with diesel and other machines in order to provide additional power input when needed. 
Synthetic inertia can be the solution through the use of storage units and appropriate controllers [7] to manage the available energy, to provide appropriate support in keeping the system stable, and to keep the variation of frequency as low as possible [8].

The main outcome of this work states that adopting smart controllers without appropriate parametrization can result in non-optimum frequency variation, which may vary even outside the acceptable limits or set the power system into an undesirable state. For this reason, further research is required to develop the appropriate methodologies capable of fine-tuning the smart frequency controllers in the field to ensure the safe and optimized operation of the power system itself.

\subsection{Literature Review}

In the literature, several efforts have been devoted to investigate different approaches for the provision of virtual inertia and frequency regulation through the design of the appropriate controllers.

In [9], a control scheme is proposed based on frequency variation and frequency derivative for a wind turbine to calculate the mechanical torque that is required to support the system's frequency. Within this controller design, droop value, and thus primary regulation, is missing. A similar scheme was proposed by Ref. [10] for a storage system to regulate frequency within a microgrid. Ref. [11] presents a fuzzy control scheme that enables the wind power inertia of a Doubly-Fed Induction Generation (DFIG) in a microgrid to support frequency under various disturbances. A sizing methodology for an energy storage system is presented in [12] in case of mixed participation to both inertial and primary control in low inertia power systems. In most of the above references, the studies of the controllers are focused to a single distributed energy resource (DER), whereas their parameters and how these are chosen are not studied thoroughly under the prism of a stable distribution grid with high-RES penetration. This is quite important as the European Union targets suggest an inverter-dominated grid in the near future where its reliability should be secured through the support of appropriately designed controllers.

Another key technique to recover frequency instead of controlling the distributed re-sources is the load shedding techniques, of which the main objective is to rebalance generation and load by shedding the appropriate number of loads. The main challenge of these schemes is to identify the amount of load with trigger signal of frequency deviation and/or the rate of change of frequency (RoCoF). There are various methods in the literature for the load frequency control, but this work is focused on research works that deal with the adaptability and definition of the related control parameters.

Uncertainty of system parameters is considered in Ref. [13] to tune more adaptive schemes of a load shedding technique. Similarly, Ref. [14] tunes the load shedding scale factor of the proposed scheme with an analytical method to achieve adaptability to different operating conditions, resulting in a more precise control. For more precise controlling, different research studies suggest artificial intelligence-based algorithms for setting the appropriate parameters. Ref. [15] proposes a robust load frequency control strategy using a fuzzy logic-based on a proportional-integral (PI) controller for an autonomous hybrid microgrid with high renewable penetration. The proposed coordinated control strategy is based on a PI controller, which is optimally tuned by using a fuzzy logic approach In [16] a genetic algorithm is employed to optimize a proportion-integral-derivative (PID) controller; in [17] the particle swarm optimization algorithm is enabled; in [18] the socialspider optimization algorithm is used; and in [19] the grasshopper optimization algorithm is employed. Ref. [20] compares the results of different controllers such as fuzzy self-tuned proportional-integral-derivative (PID) controller, fuzzy self-tuned fractional order (PID) controller, relative rate observer self-tuned fuzzy (PID) controller and relative rate observer self-tuned fuzzy.

It must be highlighted though that the above controllers are complex in nature and may not provide optimal performance as improper selection of their parameters increases the computational complexity of the algorithm. Moreover, these controllers can perform 
optimally only when a definite mathematical model of the system is available that is quite difficult for a real distribution grid.

In Ref. [21], a combination of synthetic inertia (SI) and governor control provided by wind and PV power plants was presented to show how frequency control can be implemented in bulk power systems. In Ref. [22], a virtual inertia controller version of the optimized power point tracking (OPPT) method is implemented for wind turbines, where the maximum power point tracking curve is shifted to drive variations in the active power injection as a function of both the grid frequency deviation and its time derivative.

In Ref. [23], three different control strategies of a storage system for providing Primary Frequency Regulation (PFR) have been analyzed and compared. Ref. [24] shows that a combination of automatic voltage regulation (AVR) and Synthetic Inertia (SI) offers a better improvement in frequency stability. According to the above, complex controllers are more efficient in preserving the stability of the system. However, how these complex controllers are coordinated under the distribution grid of high RES penetration is still undefined.

Based on the above, it seems that what is still missing is dealing with the frequency reservation and stability, taking into consideration the whole picture of the future grid with high penetration of distributed generation and with controllers employed that would not conflict or counteract with each other. In this case, the parameterization of such controllers is of paramount importance and such a study is valuable when performed under a realistic part of the distribution grid. But how can the different controllers optimally support the real power grid and in a complemented way?

Refs. $[25,26]$ propose solutions that can increase the hosting capacity of RES in power systems. Under this approach, a distributed control framework has been proposed, the Web-of-Cells (WoC), in which the power system is divided into smaller subsystems (cells). Each cell must contribute to balance and frequency to support the system. This implies that the distribution grid is divided in areas of control that can communicate with each other to preserve the robustness of the system.

From the above, it is derived that by employing the WoC concept for a real power grid (local controllers built under the cell concept, integrated under hierarchical levels, and cooperate in supporting the stability of the systems), can be considered as a realistic solution of technical interest. In such a case, a valid parameterization will secure the optimal cooperation of such controllers.

\subsection{Contribution/State-of-the-Art}

Considering the above, the contribution of this paper can be summarized in the following:

- Utilizing smart energy controllers and storage units to evaluate the behavior and the challenges in operating those supporting technologies on a real projection case study predicted to be representative for the Cyprus' real distribution grid during the year 2050 .

- The importance of appropriately choosing the parameters of the smart energy controllers is presented. In this way, the target of keeping the grid stable and increasing the availability and sustainability of the power grid is achieved.

- The distributed smart controllers are implemented in DERs divided in areas of control to follow the WoC concept. At the same time, hierarchical controllers are responsible for coordinating these control areas and ensuring system stability.

In addition, the contribution of this paper far beyond the research work in Ref. [7] can be summarized below:

- The projection study has been modified to include the 2050 horizon for the grid transformation. This is a key element as the system has even lower inertia and the frequency stability reservation is more challenging for the employed controllers.

- As such, the parametrization of the controllers is of paramount importance as the characteristics of the 2050 grid dictates precise and robust controllers.

- The WoC concept is enabled to foster the controllers' actions and cooperation, and ensure complementarity of actions. 
The scenarios adopted evaluate the behavior of the frequency with and without applying the proposed frequency regulation methods while imposing the power grid into anticipated faults/disturbances. From the simulation work and recorded results, it is observed that the smart energy controllers can succeed in maintaining the frequency within the desirable range through appropriate use of controlled resources under stressful conditions in a high RES rate environment. The derived results are evaluated through dedicated performance indices related to frequency variation, such as the rate of change of frequency (RoCoF) and frequency Nadir. Time-series data are obtained via performing simulation studies on the physical system and while applying expected disturbances. In this way, the responsiveness of the applied solution is evaluated and justified.

In general, this paper is structured as follows: In Section 2, the methodology adopted is presented in relation to the structured case study used to evaluate the presented results. Details for the simulated grid used in performed simulations and evaluations are also given. Section 3 provides the simulation case results with related plots and analysis. Section 4 discusses the achieved results, giving evidence of the implications that are identified though applying the smart controllers on the representative Cyprus grid model. Finally, Section 5 addresses the conclusions that can be drawn from the presented work and the general outcomes that validate the adapted solutions.

\section{Methodology-Case Study}

In this work, a case study was developed based on the real projection for the Cyprus electricity grid. The aim was to develop the simulation scenario and undertake an adequate number of simulations with/without smart frequency controllers after imposing the electricity grid model into faults/disturbances. This presented the importance of tuning correctly the parameters/parametrization of frequency controllers in the context of the whole power network and not just individually. An optimization algorithm was employed to produce two sets of controller parameter values with different key performance indices (KPIs) responses to highlight the importance of tuning the controller parameters appropriately by developing dedicated online or offline methodologies. The simulation results were evaluated with the help of KPIs which are shown in Table 1. The chosen KPIs were adopted in order to depict the differences between various configurations/parametrizations. In more detail, RoCoF and Nadir are well-used indices in assessing the behavior of frequency [27-29]. The Nadir index represents the lowest frequency value obtained during a power disturbance. On the other hand, RoCoF measures the frequency gradient/rate of change during and after the occurrence of the power event. The variation of RoCoF depends on the system inertia, the response of the available power reserves, the response of primary frequency control systems, the size/location of the disturbance, etc.

Table 1. Key Performance Indices (KPIs).

\begin{tabular}{|c|c|c|c|}
\hline \multirow{3}{*}{ Key Performance Index } & ID & Name & Formula \\
\hline & 1 & Frequency Nadir & $\begin{array}{l}\max \left(f_{n}-f\right)[\mathrm{Hz}] \\
f_{n}-\text { nominal frequency }[\mathrm{Hz}] \\
f-\text { system frequency }[\mathrm{Hz}]\end{array}$ \\
\hline & 2 & $\begin{array}{l}\text { Rate of Change of Frequency } \\
\text { (RoCoF) }\end{array}$ & $\begin{array}{l}\frac{d f}{d t}=\frac{P_{g}-P_{l}}{2 H_{\text {sys }}} \\
\frac{d f}{d t}-\text { rate of change of frequency }[\mathrm{Hz} / \mathrm{s}] \\
P_{g}-\text { generators' active power }[\mathrm{pu}] \\
P_{l}-\text { demand active power }[\mathrm{pu}] \\
H_{\text {sys }}-\text { system inertia }[\mathrm{s}]\end{array}$ \\
\hline
\end{tabular}

The undertaken steps for the whole process are presented in Figure 1. Specifically, the time step was set to the initial time stamp of the time-series data related with the power production of system elements and then a load flow simulation was performed via DIgSILENT PowerFactory software package. After that, a Root Mean Square (RMS) 
simulation was undertaken during which a power disturbance was imposed in one of the areas of the electricity network under investigation. The results were stored, and the time step was increased to the next time moment to repeat the load-flow and RMS simulations. The simulations were repeated until all scenarios under investigation were completed. The obtained results were statistically analyzed according to the KPIs defined in Table 1. In the following subsections, the parameter estimation process, the grid system, the scenarios and the control schemes are described.

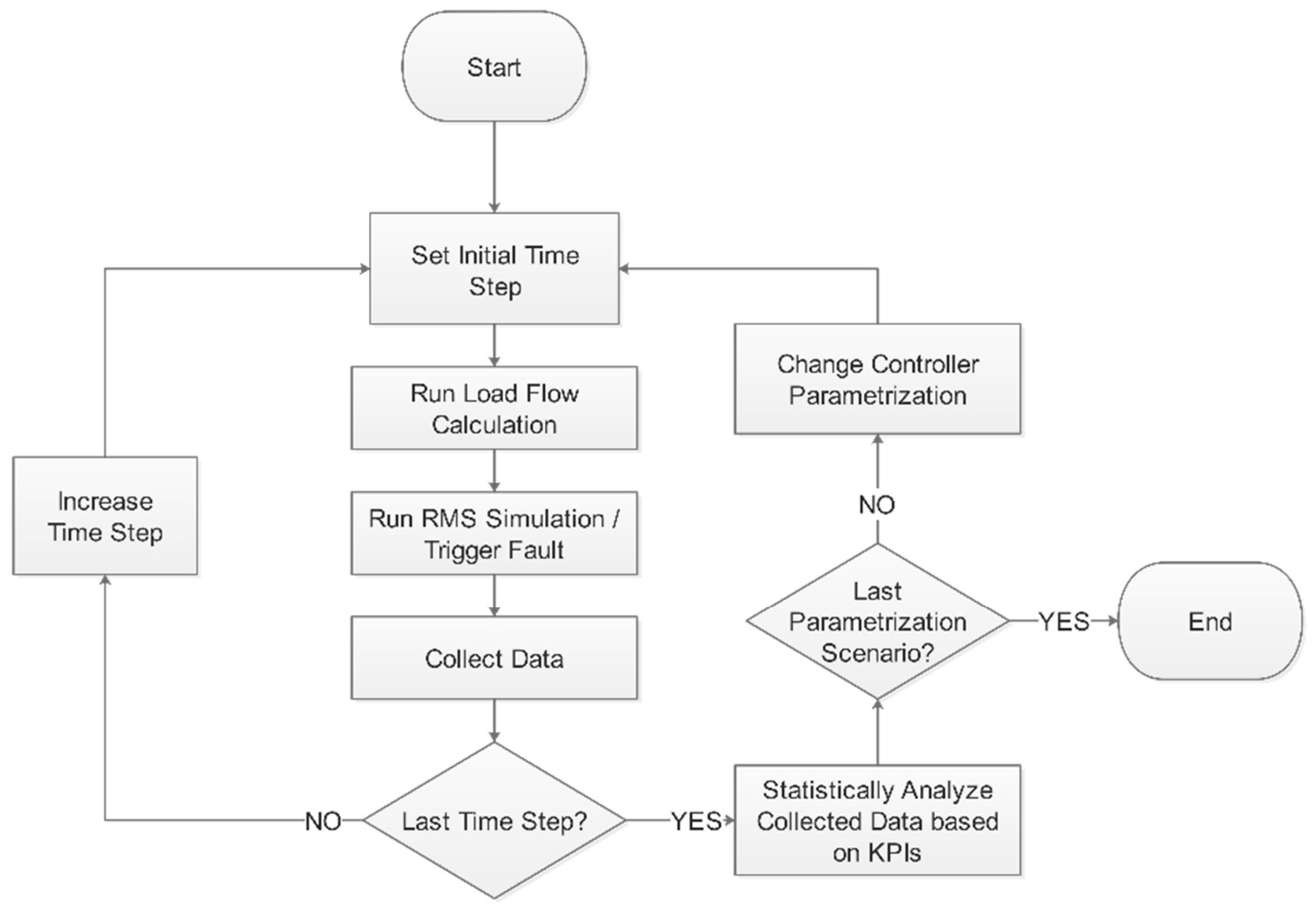

Figure 1. Flowchart for simulation/analysis process.

\subsection{Parameter Estimation via the Nelder-Mead Algorithm}

The parameters of the controller along with the RMS simulation data produced by imposing the distribution grid model under investigation into single fault events were used in forming a parameter estimation problem. By adjusting the parameters of the controllers via the help of the Nelder-Mead simplex (NMS) algorithm, it became possible to identify parameter sets that produce a frequency response characterized by better KPIs. In more detail, the target of the algorithm was to minimize the main KPIs (Nadir, zenith and steadystate value) in such a way as to produce sets of values for the controller parameters having one set with better response in KPIs than a second set. The cost function was formulated by the following equations, which considers a k number of time steps to achieve a more global optimization solution for the adopted time series data. The cost function is described by Equations (1) and (2) as follows:

$$
\begin{gathered}
c_{\text {time step }}^{i}=w_{\text {nad }} \cdot\left(f_{\text {nad }}^{i}-f_{\text {nom }}\right)^{2}+w_{\text {zen }} \cdot\left(f_{\text {zen }}^{i}-f_{\text {nom }}\right)^{2}+w_{\text {ss }} \cdot\left(f_{\text {ss }}^{i}-f_{\text {nom }}\right)^{2}, \\
\mathrm{CF}=\sum_{i=1}^{k} c_{\text {time step }}^{i}
\end{gathered}
$$


where

$\mathrm{CF}=$ Cost function,

$c_{\text {time step }}^{i}=$ cost function for time step $i$,

$f_{\text {nom }}=$ nominal frequency,

$w_{\text {nad }}, w_{\text {zen }}, w_{s S}=$ weights for Nadir, zenith and steady state sub-cost function, respectively,

$f_{\text {nad }}^{i}=$ Nadir value (minimum frequency value during abnormal event) for time step $i$,

$f_{z e n}^{i}=$ zenith value (maximum frequency value during abnormal event) for time step $i$, step $i$

$f_{s S}^{i}=$ steady state value (final stabilized frequency value after abnormal event) for time

In general, the NMS simplex forms the problem as a geometric shape of nonzero volume which is composed of $n+1$ vertices. Initially, the algorithm starts with a set of random values and consequently the initial conditions $=$ are affecting the convergence time of the estimation process. At every new iteration, NMS generates a new vertex based on the objective function performance of simplex vertices. Subsequently, the algorithm replaces one of the existing vertices with a new one, and so the process evolves. The objective function is calculated at each vertex and the vertex with the highest value is replaced by the new one. The NMS simplex is rescaled based on four basic actions: reflection, expansion, contraction and shrinkage, depicted in Figure 2. More information can be found in [30-33].

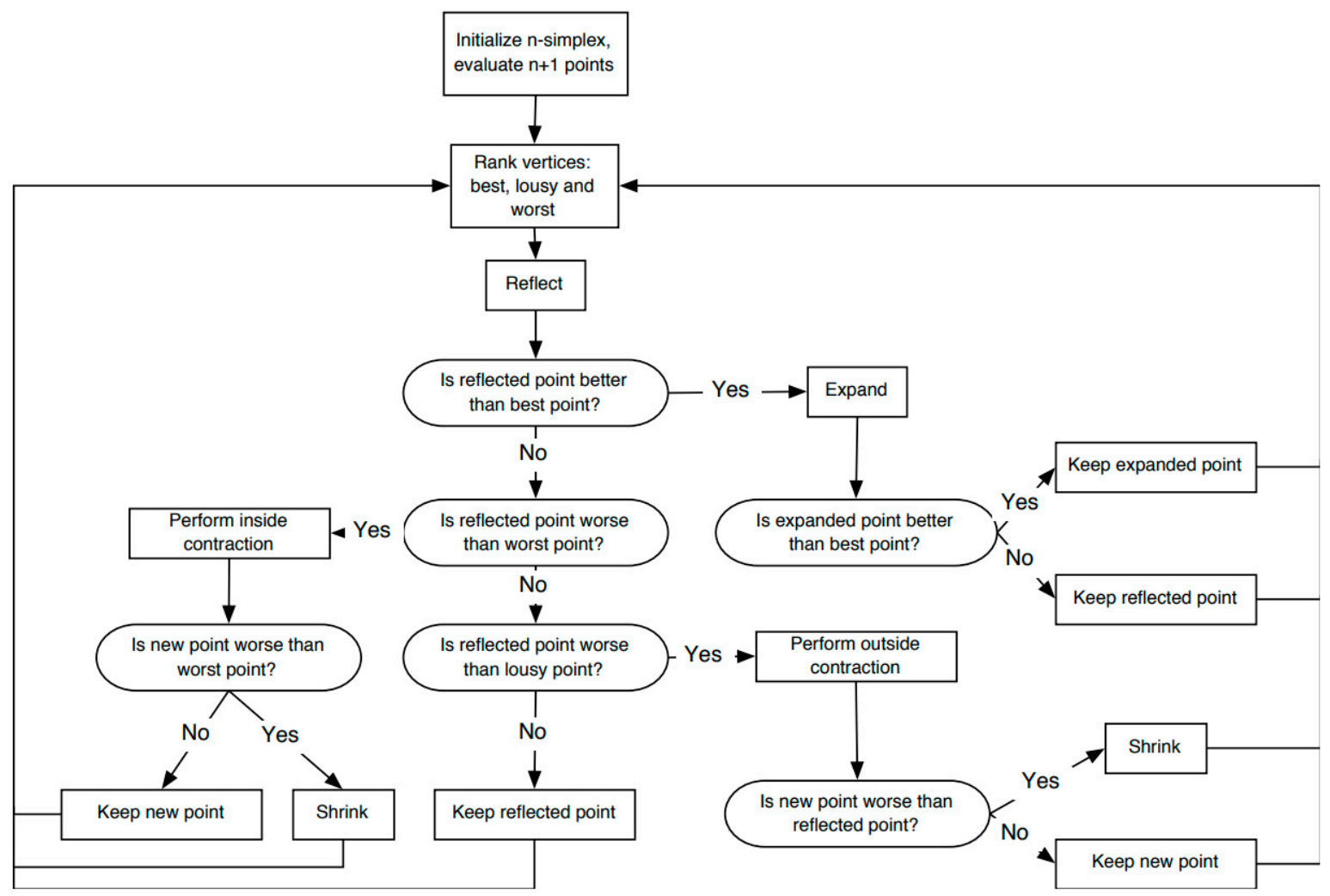

Figure 2. Flowchart of Nelder-Mead simplex algorithm [34].

\subsection{Selected Section of the Cyprus Grid System}

The electricity grid system represented by the formulated grid model was based on the transmission and distribution grid topologies of the Electricity Authority Cyprus (EAC) power network. The grid system is a selected section of the real grid circuits of 2019 Cyprus power network and it contains transmission substations operating at $132 \mathrm{kV}$ voltage levels and distribution substations with voltage terminals of $22 \mathrm{kV}, 11 \mathrm{kV}$ and $400 \mathrm{~V}$ phase to phase. Specifically, it includes the distribution network of three transmission substations of Cyprus: ALAMBRA-Area1, PROTARAS-Area 2 and DISTRICT OFFICE-Area 3. 
These substations were suitable and selected to represent all possible topologies of the Cyprus grid. ALAMBRA s/s serves a rural set of consumers with extensive lengths of overhead lines and pole mounted transformers, PROTARAS s/s serves a highly touristic synthesis of consumers with a mixture of overhead and underground medium and low voltage grid, and lastly DISTRICT OFFICE s/s serves an urban set of consumers with most of the medium and low voltage grid deployed underground with ground mounted substations. Figure 3 presents a part of the PROTARAS distribution network which includes the transmission substation (marked with $\mathrm{S}$ symbol) and distribution substations.

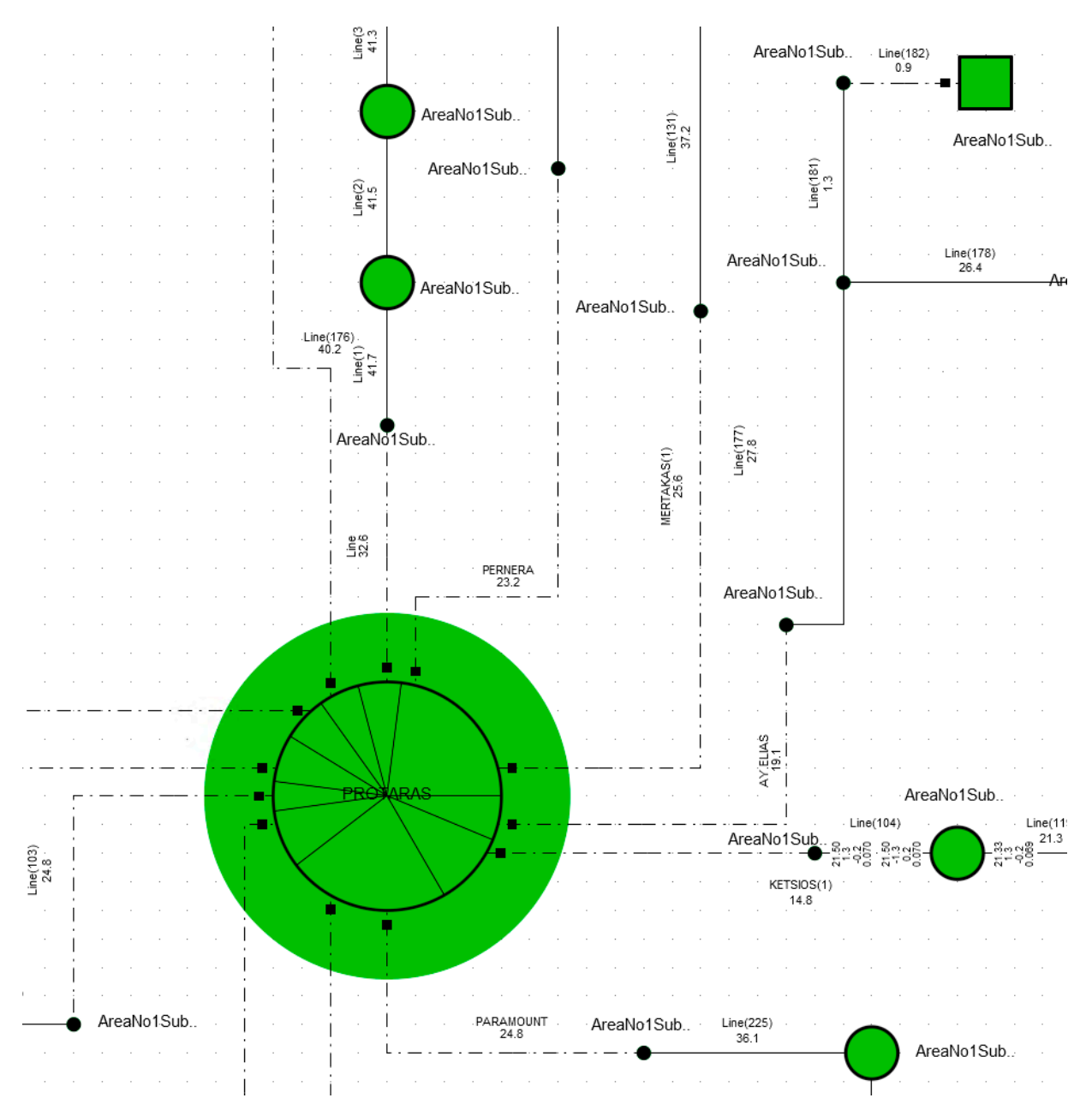

Figure 3. Transmission Substation and Distribution Substation models for PROTARAS distribution network.

Furthermore, the distribution system of Cyprus has a radial form and the transmission system has a ring structure, which was exactly reflected on the proposed grid model under investigation. The top level of the power grid operates at $132 \mathrm{kV}$ nominal voltage and is designed to support the $n-1$ operating criterion to ensure the security of supply under faults. On the other hand, the distribution grid uses two operating nominal voltages, 11 and $22 \mathrm{kV}$, respectively, and the low-voltage system operates at $400 / 230 \mathrm{~V}$. It is to be clarified that Cyprus is in the process of upgrading the medium voltage system from $11 \mathrm{kV}$ to $22 \mathrm{kV}$ and for this reason all equipment installed is insulation ready for the $22 \mathrm{kV}$ system, but upgrading is done selectively following a strategic plan for the whole of Cyprus. Where the system is operating in transition, suitable interbus transformers (at $11 \mathrm{kV}$ to $22 \mathrm{kV}$ of adequate power and automatic voltage regulation where required) were used to facilitate the quality operation of the two voltage systems.

The power is distributed via the distribution network to customers via overhead or underground cables, based on the respective European standards using effectively earthed 
systems. For the distribution substations, standardized designs are adopted belonging into two categories: (a) the ground mounted substations ranging from 300 to $1000 \mathrm{kVA}$ capacity and (b) the pole mounted substations ranging from a 25 to $200 \mathrm{kVA}$ capacity.

\subsection{The Grid Model Used for the Analysis}

The selected grid model is based on the three transmission substations (ALAMBRA, PROTARAS and DISTRICT OFFICE referred to above) that include a total of 1721 lines, 3011 busbars (4893 terminals), 1008 transformers, 1925 loads (containing 962 electric vehicle loads), and 1933 generators (962 PV systems, 2 Synchronous machines, 962 battery energy storage systems, 2 Hydro systems, 2 Wind Farm systems and 3 biomass units). It also contains 2284 protection devices (993 fuses) and 1291 breakers/switches.

Each transmission substation is a separate control area with distributed generation, storage, electric vehicles and loads (divided promotionally along distribution substations based on distribution transformer rating). The model of the standardized distribution substation topology is shown in Figure 4 and it incorporates a distribution transformer and aggregated elements for load, electric vehicles, photovoltaic systems and storage units.

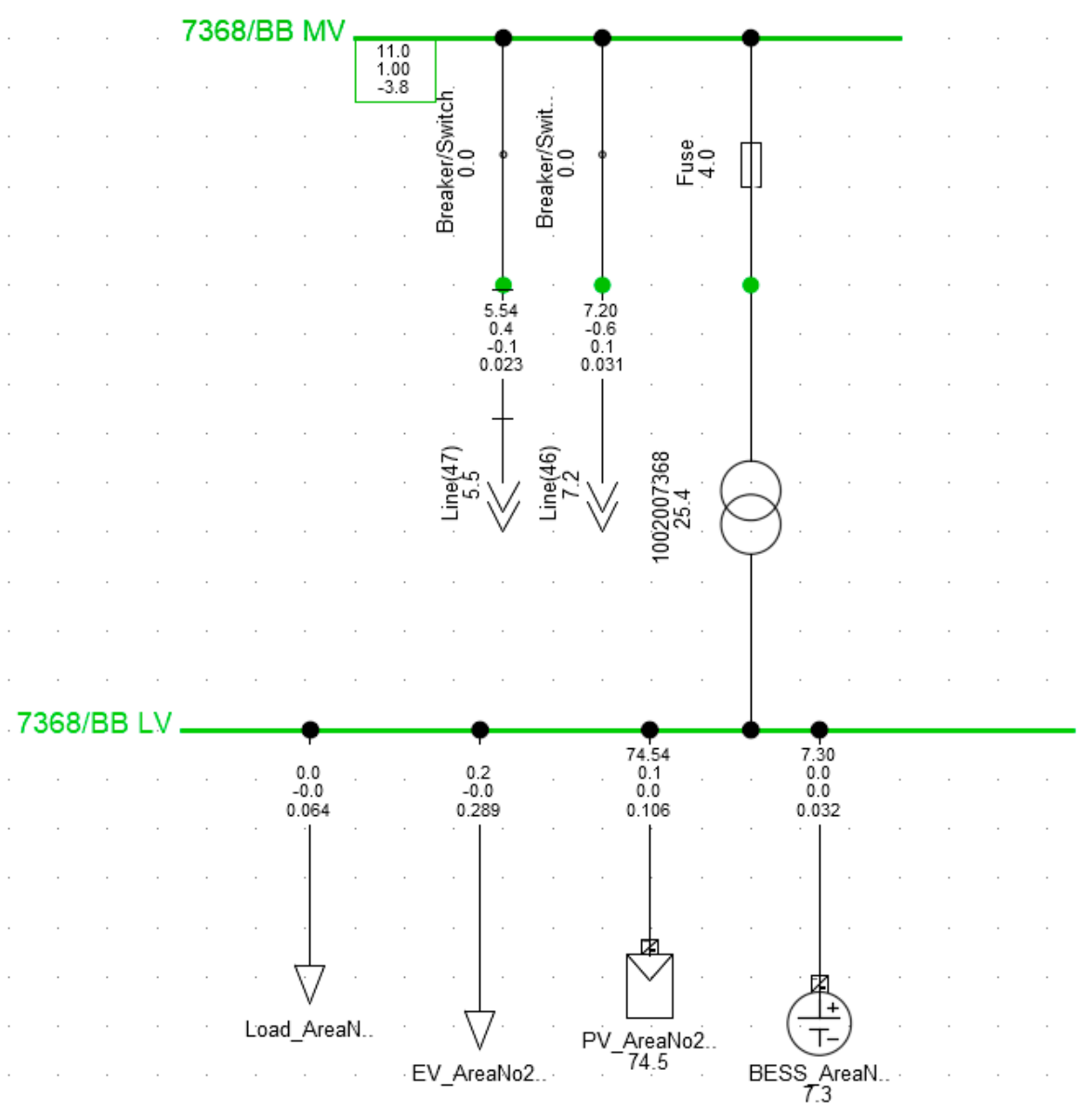

Figure 4. Standardized Distribution Substation topology.

The proposed grid model also includes a conventional power generation and a wind power generation area shown in Figures 5 and 6, respectively. The conventional power generation area is composed of two transmission transformers and two synchronous machines. In addition, the wind power generation area includes one transmission transformer and two aggregated wind turbine units. 


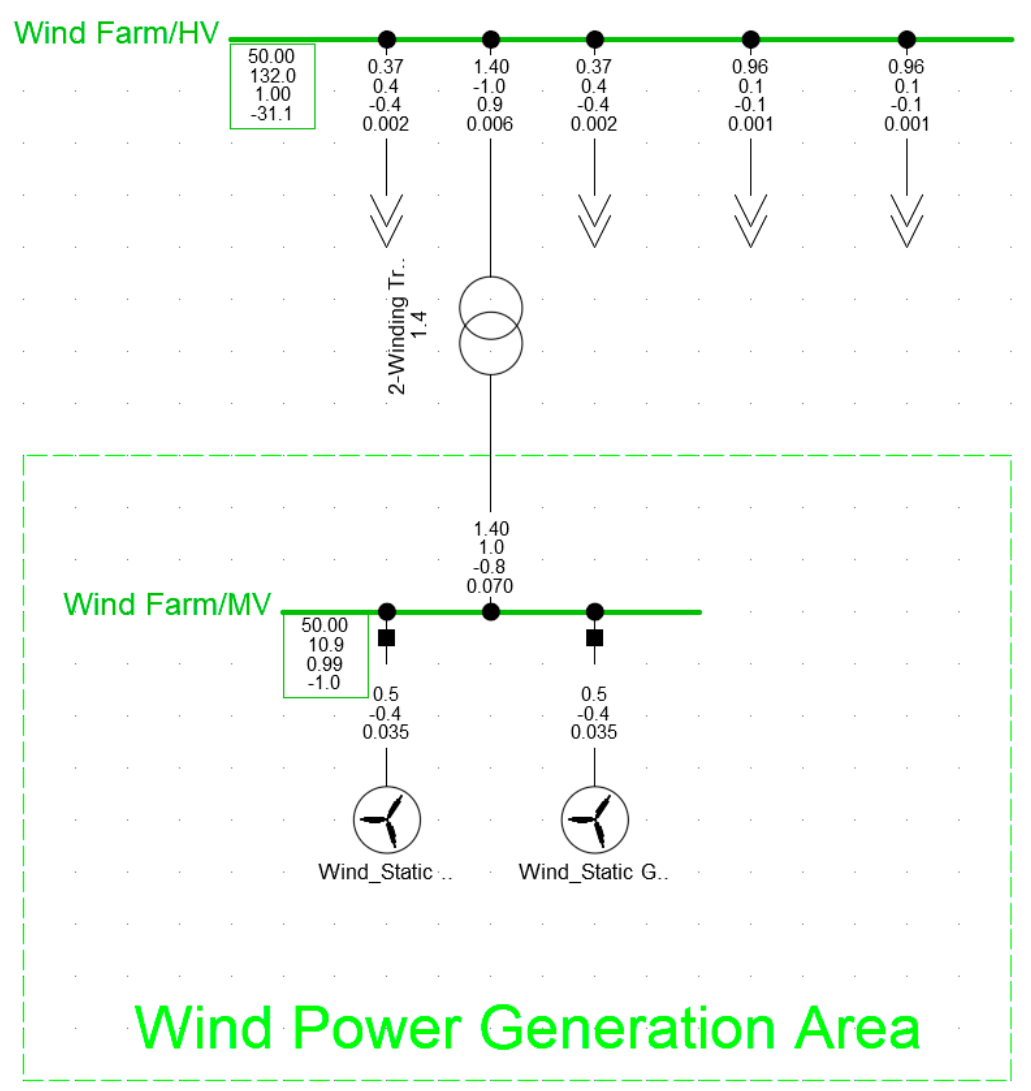

Figure 5. Model of Wind Power Generation Area.

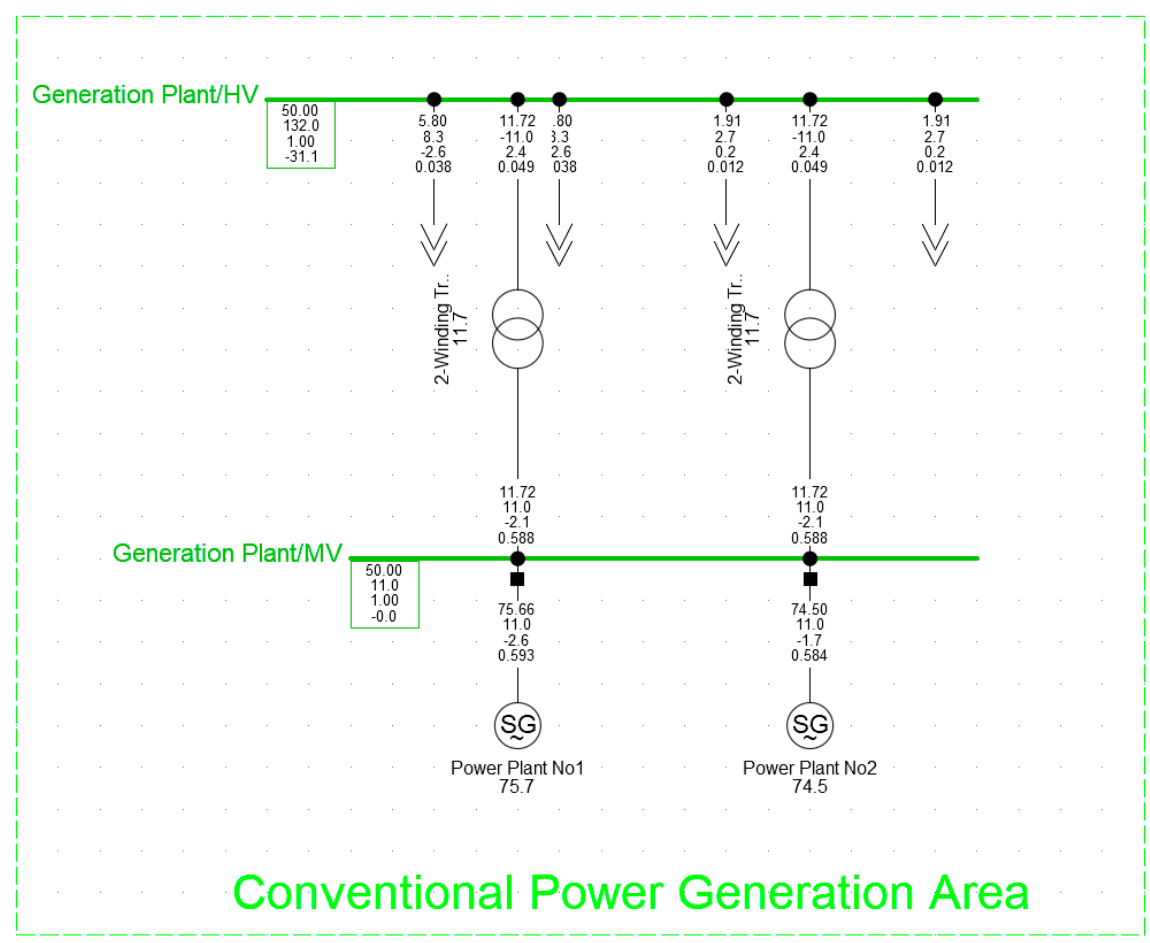

Figure 6. Model of Conventional Power Generation Area. 


\subsection{Scenario}

For the investigations, the 2050 projection was utilized, of which the production per power source is shown in Table 2.

Table 2. Scenario for 2050—Nominal Power Production per type.

\begin{tabular}{ccccccc}
\hline \multicolumn{7}{c}{ Nominal Capacity Per Power Source Type (MVA) } \\
\hline $\begin{array}{c}\text { Scenario } \\
\text { Cases }\end{array}$ & Solar & Wind & Hydro & Biomass & Conventional & $\begin{array}{c}\text { Pump } \\
\text { Storage }\end{array}$ \\
\hline 2050 & 47.8 & 47.8 & 33.6 & 6.2 & 38.0 & 15.6 \\
\hline
\end{tabular}

In order to evaluate the response of frequency controllers under different parametrizations, two power events are defined. Those events simulate conditions and challenges that can occur in a realistic case. The defined events are depicted in Table 3.

Table 3. Power Events under investigation for 2050 Scenario.

\begin{tabular}{ccc}
\hline \multicolumn{2}{c}{ Stability Analysis Scenarios for $\begin{array}{c}\text { 2050-Loss of Generation Capacity (Affected Source Type } \\
\text { Marked with Grey Color) }\end{array}$} \\
\hline Source Type & Fault in Area 1 & Fault in Wind Station \\
\hline Solar & 47.8 & 47.8 \\
Wind & 47.8 & 47.8 \\
Hydro & 23.5 & 23.5 \\
Biomass & 4.4 & 4.4 \\
Pumped Storage & 10.9 & 10.9 \\
Conventional & 26.6 & 26.6 \\
\hline
\end{tabular}

\subsection{Control Scheme}

With the introduction of renewable energy resources and distributed power generation, the management of frequency will stop to be centralized. This will impose new challenges to system operators, and new types of frequency controllers and monitoring systems will need to be installed and enabled to achieve proper and adequate frequency regulation.

Consequently, under the unavoidable transformation of the grid, a new decentralized control architecture is needed to be developed and all possible affecting parameters need to be defined and assessed. The decentralized control architecture requires the local power issues to be handled locally by utilizing local controllers and local energy resources in the majority of cases.

The smart and decentralized frequency controller presented in [7] is adopted in investigating further possible problems related with the frequency regulation while a local concept is being applied. The aim of the specific controller is to use distributed resources present in the grid to solve the frequency instability problems. The parametrization of the controllers is altered accordingly to reveal any possible issues related with the adequate/proper frequency regulation. The aforementioned control scheme is depicted in Figure 7 with the main functions noted.

As shown in Figure 7, the main local controller functions are:

- Event Location;

- $\quad$ fFRC_-fast Frequency Restoration Control;

- Pre-defined Power-Frequency curve calculation;

- Local Resources Control; 


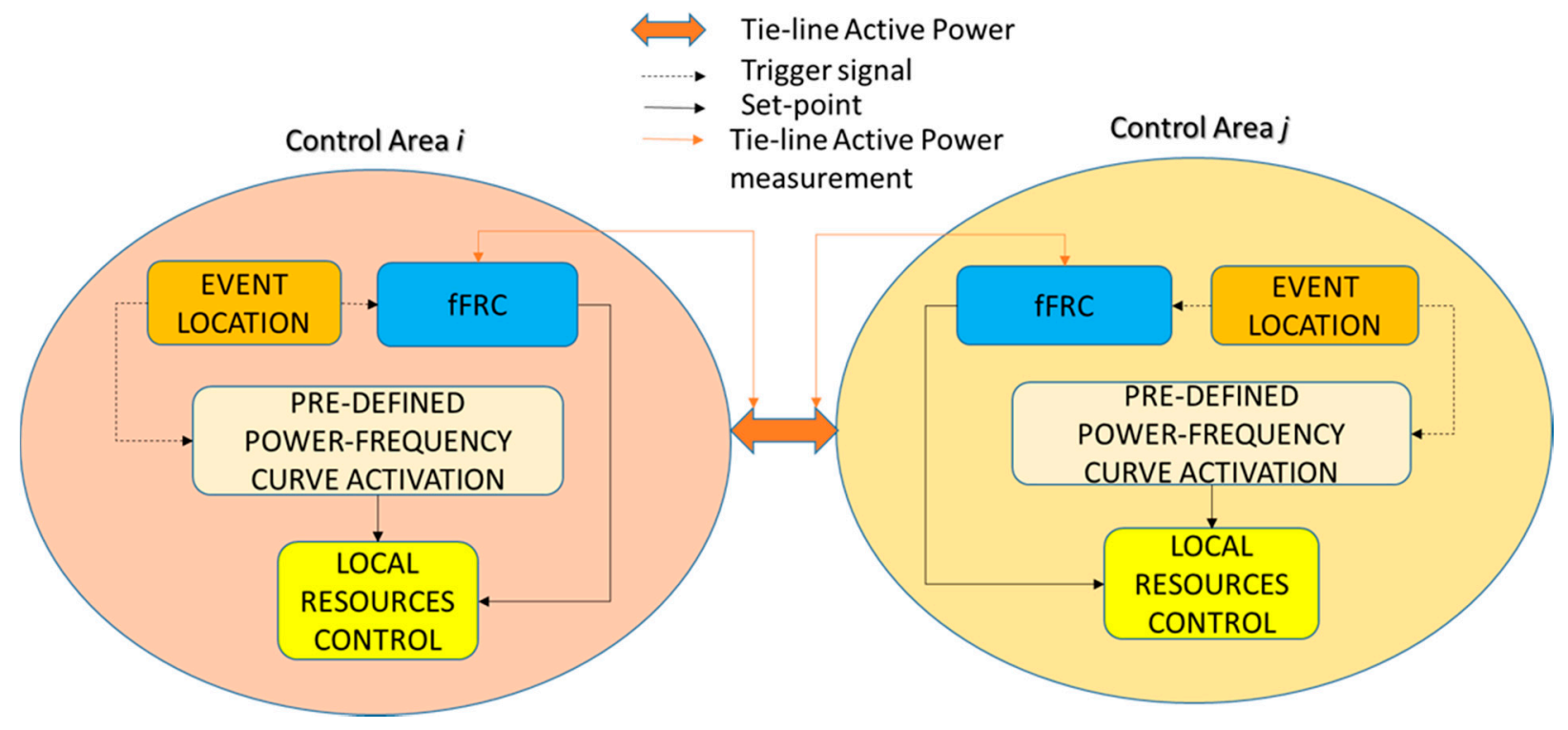

Figure 7. Control logic scheme [7].

Figure 8 shows the control area level with the main functions and their interconnections highlighted.

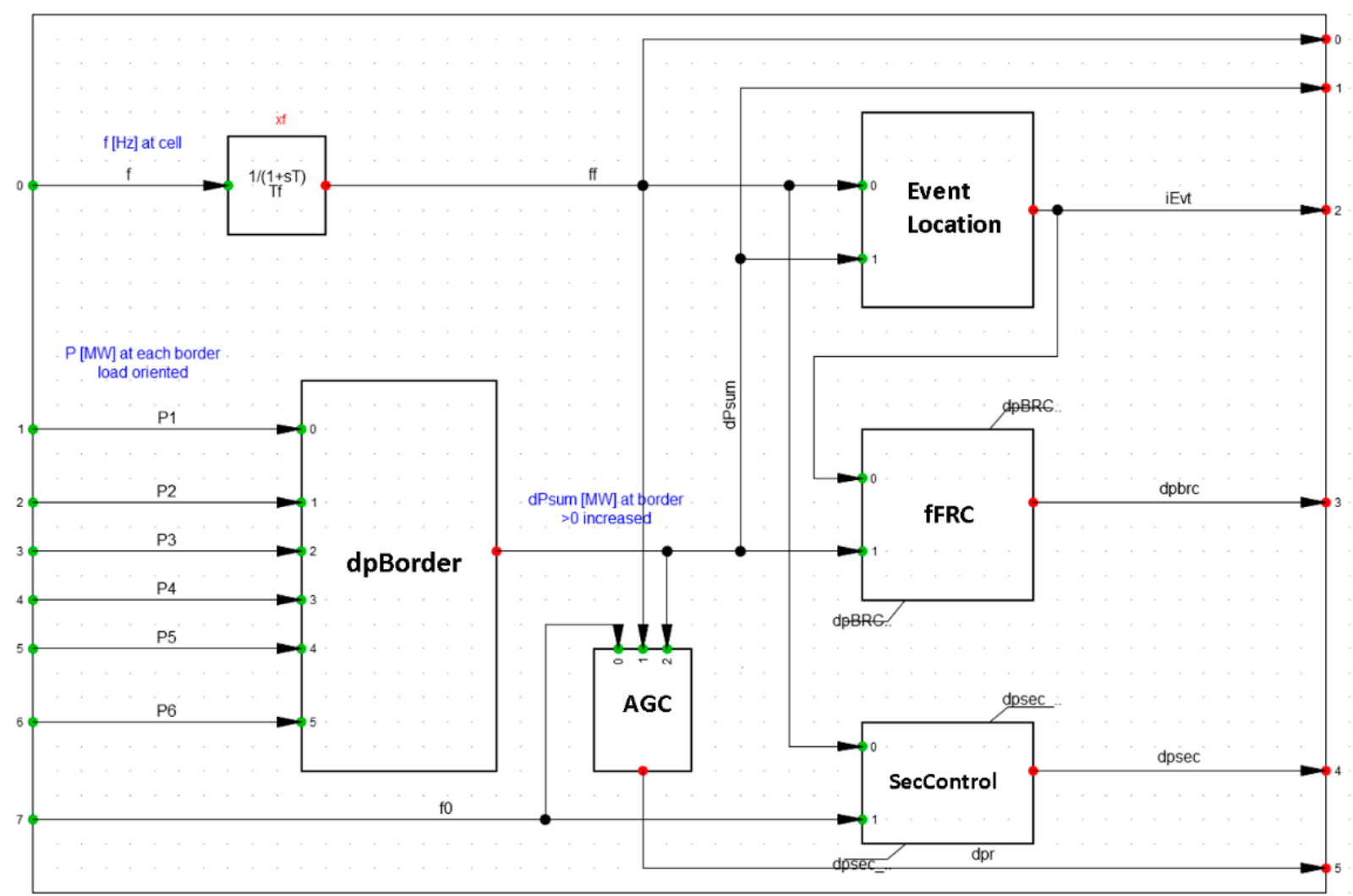

Figure 8. Functions and Interconnections of area controller [7].

Figure 9 shows the communication interface that allows the interaction between control area level and local resources level. 


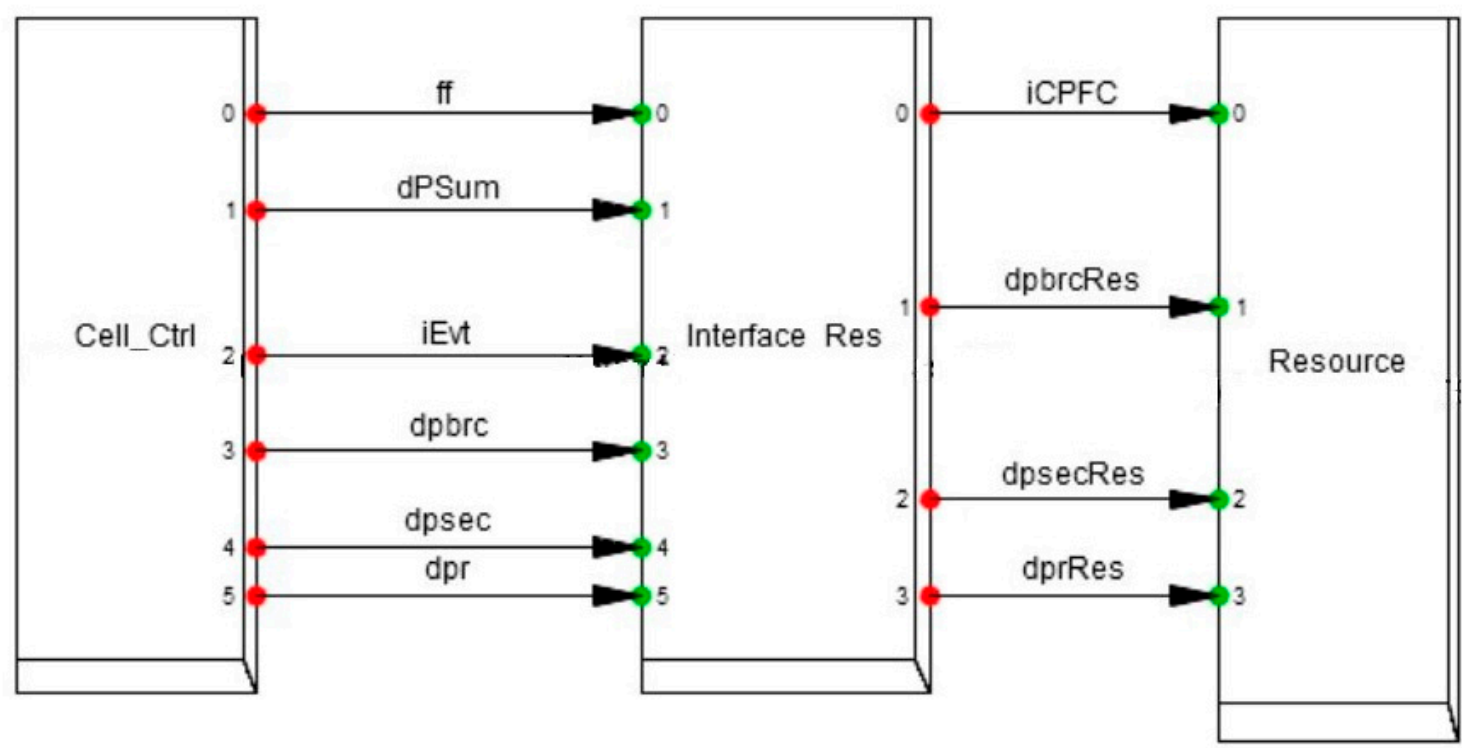

Figure 9. Communication Interface Level [7].

Figure 10 presents the local resource control of which the parameters are imposed into fine-tuning via the optimization method described in Section 2.1 "Parameter Estimation via the Nelder-Mead algorithm" to activate better frequency regulation results.

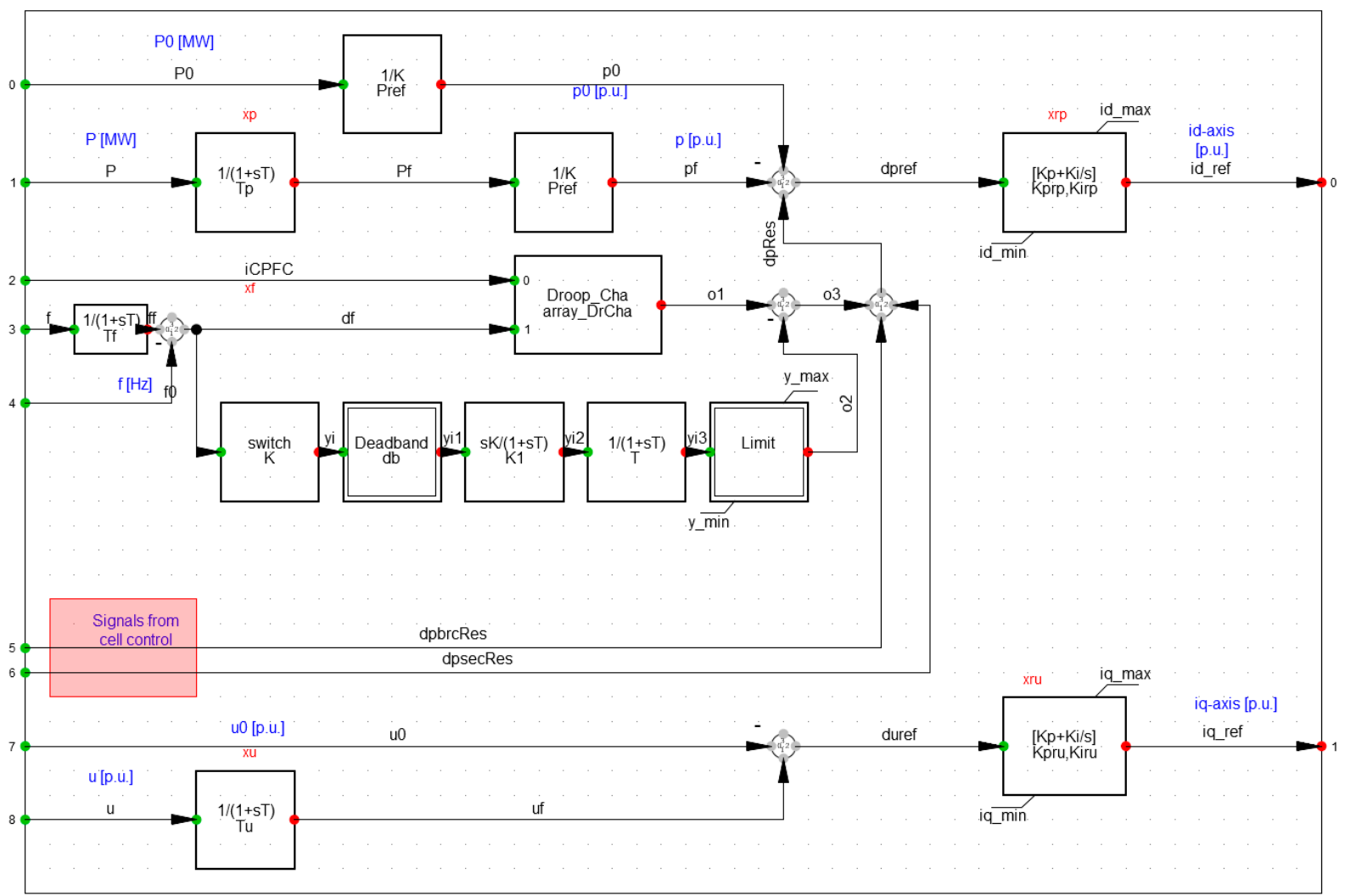

Figure 10. Local Resources Control [7].

More information about the adopted controller can be found in [7]. 


\section{Simulation Case Results}

From the simulation results, it was observed that when a significant loss of load/power generation occurs, the frequency regulation with smart controllers is mandatory. Such a behavior is expected in systems with high penetration of RES and consequently low total inertia, especially when the fault/disturbance causes a significant power variation.

Therefore, not only the frequency stability but also the frequency response needs to be controlled within the acceptable range via the available distributed energy resources in the best way possible. Advanced controllers need to be adopted and the appropriate parametrization needs to be found in order for the behavior of the frequency controllers, in the context of the whole power network, to be the most optimal and most effective in improving the frequency variation during and after the occurrence of a power event. From the results of frequency variation shown in Figure 11, it is observed that the local control approach manages to minimize the frequency drop effectively when the proper parametrization is achieved. It must be noted that the abbreviations shown in Figure 8 are referring to the study cases as follows:

- $\quad$ A1-CD-NP: Area No 1-Controllers Deactivated

- A1-CA-WP1: Area No 1-Controllers Activated-Wrong Parametrization No 1

- A1-CA-GP: Area No 1-Controllers Activated-Good Parametrization

- WSA-CD—NP: Wind Station Area-Controllers Deactivated

- WSA-CA-WP1: Wind Station Area-Controllers Activated-Wrong Parametrization No 1

- WSA-CA-GP: Wind Station Area-Controllers Activated-Good Parametrization

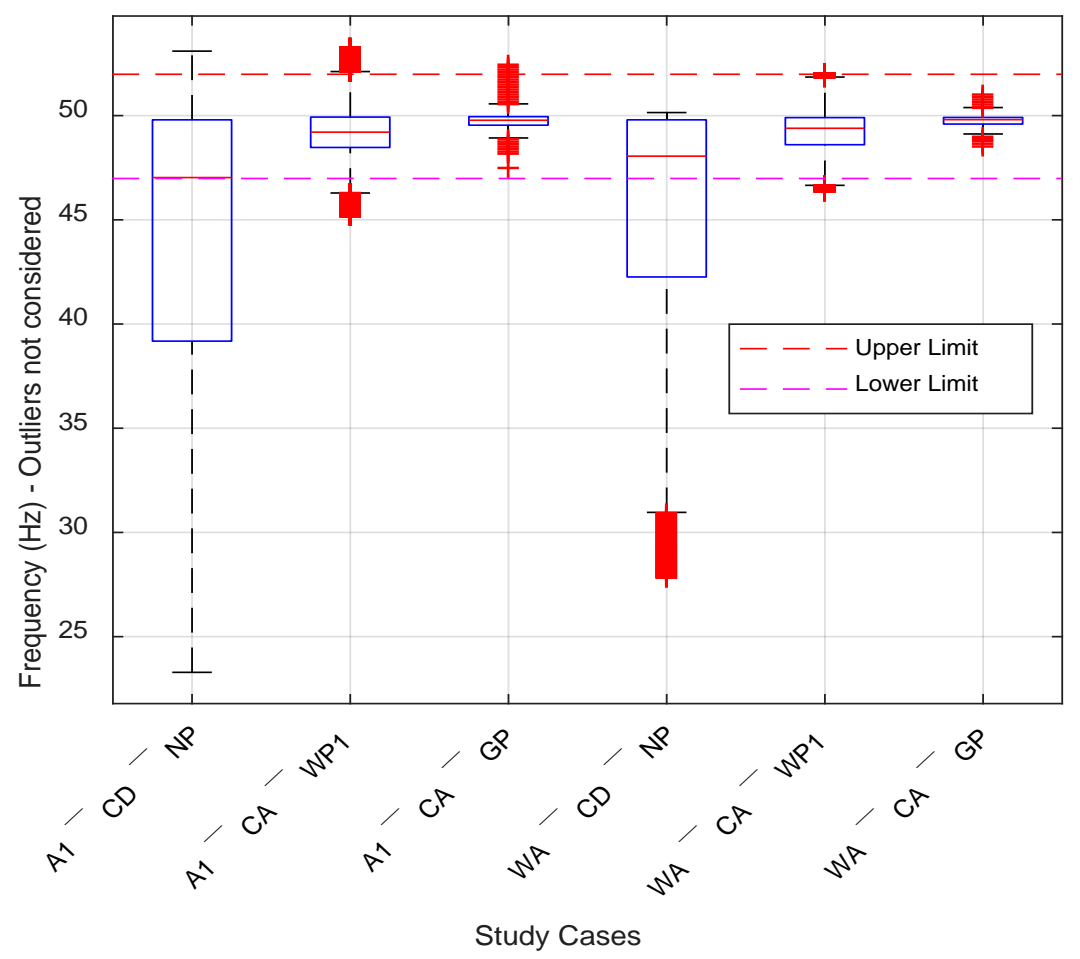

Figure 11. Frequency variation during the disturbance events while not adopting the controllers and while adopting controllers with wrong/good parametrization (Box Plot Format)—All Study Cases.

Furthermore, the frequency of Nadir is being reduced significantly for almost all cases as shown in Figure 12, but it is obvious that the sustained amplitude is affected by the parametrization of frequency controllers. Additionally, in Figure 13 it can be derived that if the controllers react on the appropriate time, lower values of RoCoF can be achieved in the majority of cases, both negative and positive, respectively. 


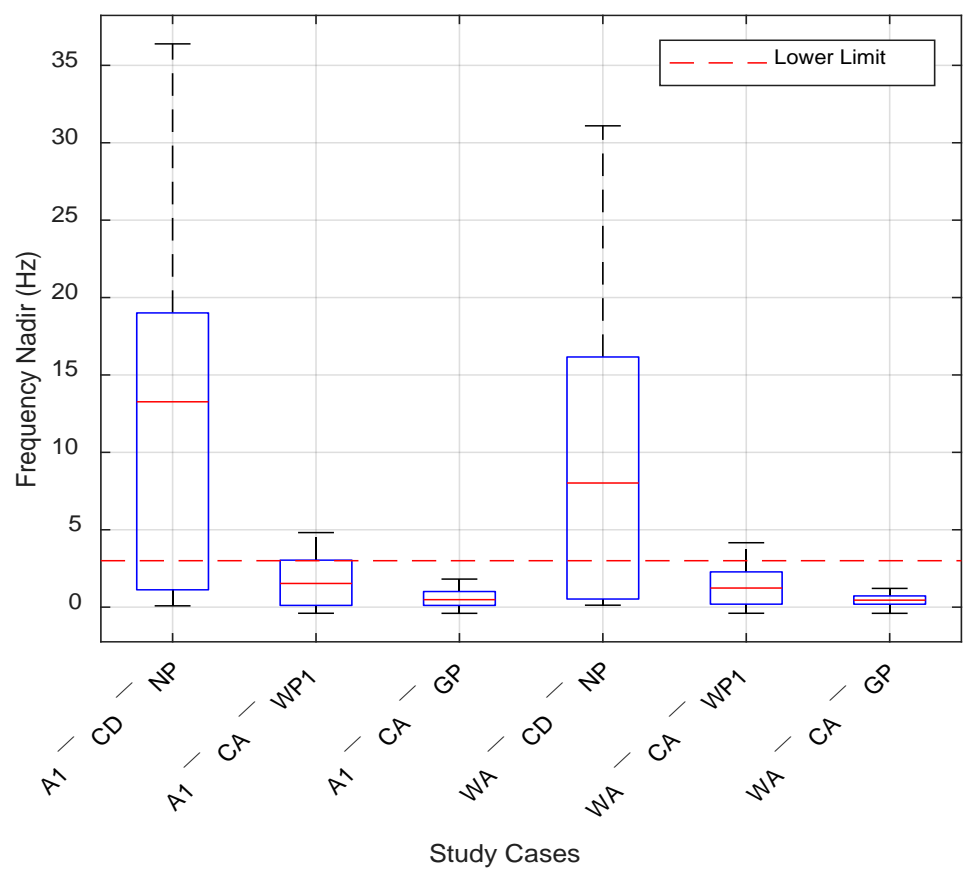

Figure 12. Nadir variation during the disturbance events while not adopting the controllers and while adopting controllers with wrong/good parametrization (Box Plot Format)_All Study Cases.

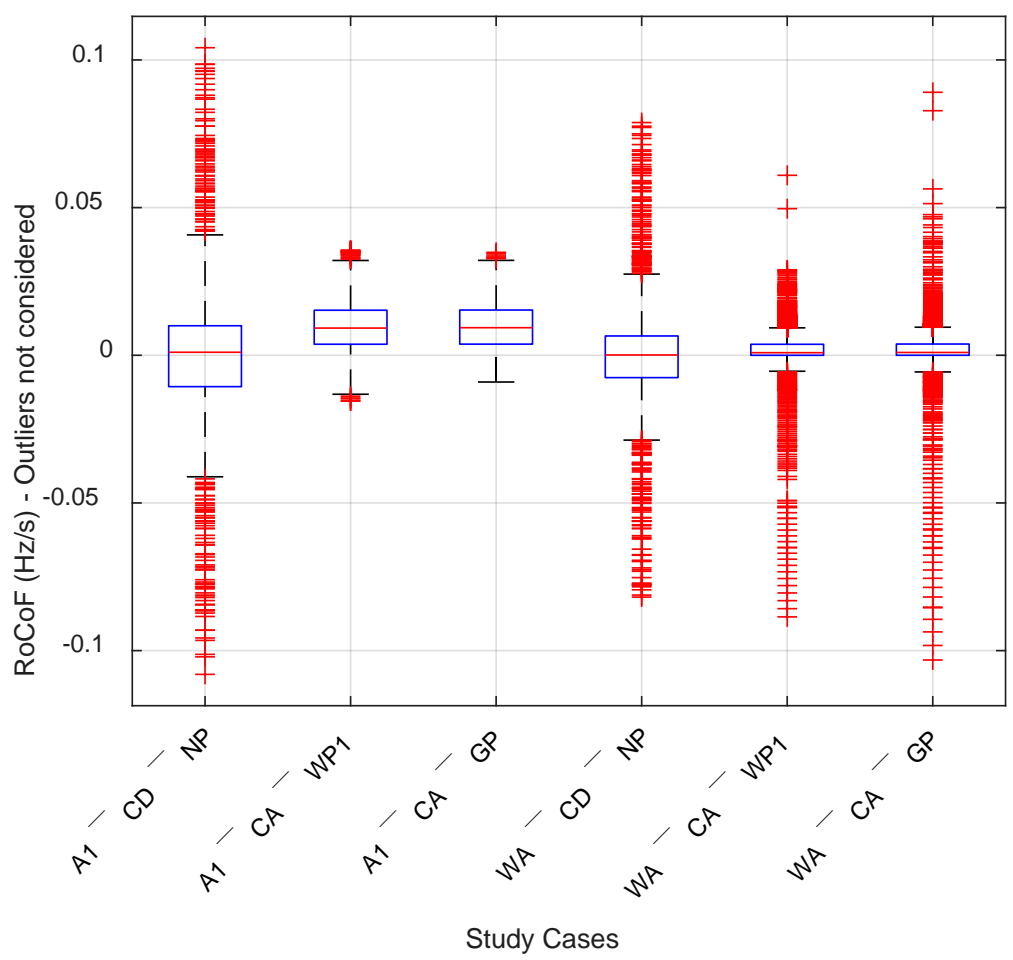

Figure 13. Rate of change of frequency (RoCoF) variation during the disturbance events while not adopting the controllers and while adopting controllers with wrong/good parametrization (Box Plot Format)-All Study Cases.

Figures 14 and 15 present two fault events and their respective achieved correction based on different simulated controller cases. The time evolution of events reveals clearly how a controller with proper parametrization can improve the frequency trajectory and the corresponding steady state response. 


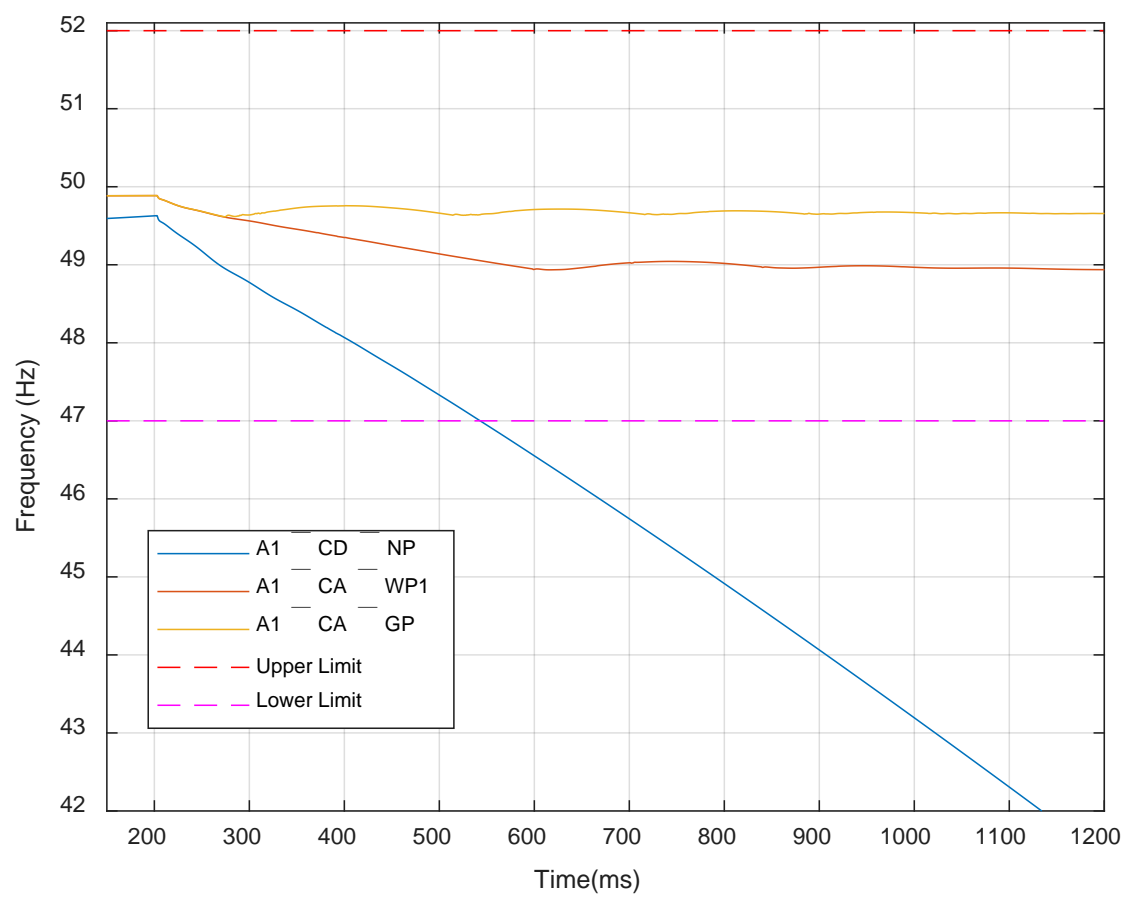

Figure 14. Frequency vs. Time while not adopting the controllers and while adopting controllers with wrong/good parametrization (Box Plot Format)—Event No 1-Severe reduction of frequency.

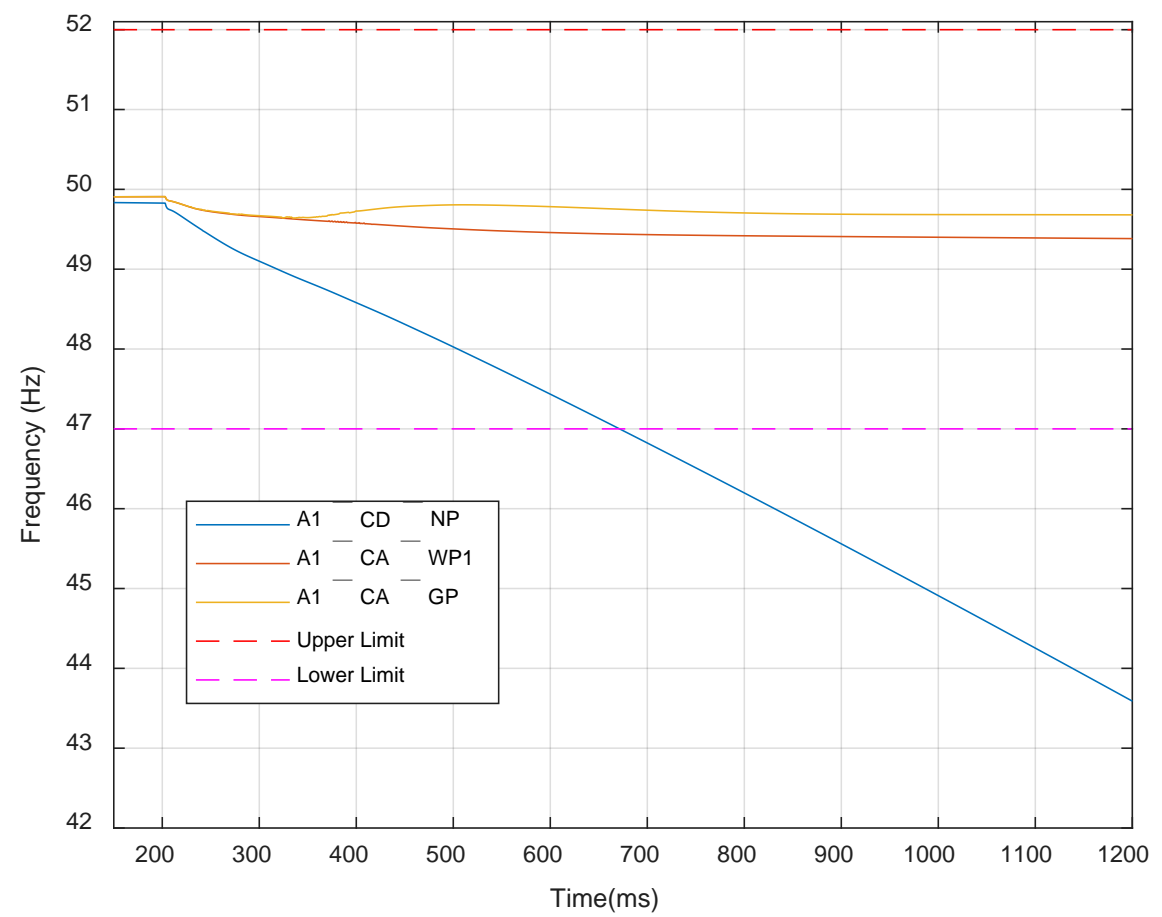

Figure 15. Frequency vs. Time while not adopting the controllers and while adopting controllers with wrong/good parametrization (Box Plot Format)-Event No 2-Less severe reduction of frequency.

\section{Discussion}

The developed system for 2050 projection was evaluated thoroughly in the presence of smart frequency controllers with different parametrization and under different operational disturbances. Based on the results, the following outcomes were derived:

- Results of frequency variation showed that the frequency controllers adopted can minimize the frequency variation effectively. 
- The steep frequency variation was avoided in a statistically higher number of cases when the parametrization of controllers was the appropriate one.

- The controllers forced the frequency to get into the acceptable range, causing lower RoCoF values if the correction by the controllers was undertaken on time.

- It was justified and verified that the frequency controllers were mandatory for achieving frequency regulation within the desired range.

- The frequency Nadir was reduced significantly if the controllers were tuned appropriately.

- The overall frequency stability was improved with the utilization of smart frequency controllers.

- The smart frequency controllers can be effective in regulating frequency levels within acceptable ranges and therefore reduce the danger of major/partial shutdown of the power grid.

- The smart frequency controllers must be designed accordingly to be able to cope with the event/fault types always in coordination with the hierarchical control regime of the system.

\section{Conclusions}

The low inertia emerging systems contribute a major challenge for the grid network as they can negatively affect the system frequency and cause critical stability issues on the operation of the power grid.

The major contribution of this paper lies in the evaluation of aspects affecting the capability of smart controllers in contributing to the regulation of frequency and coping with operational disturbances. Adequate details for the controllers and methodology adopted are presented to help the reader understand the purpose and value of the work undertaken. In particular, the paper presents the evaluation of results obtained while adopting smart controllers with different parametrizations. In order to achieve the simulation case goal, the following are provided:

- A methodology for evaluating the performance of smart frequency controllers responsible for the stability of power systems.

- A real simulation case which includes an extended power grid composed of both transmission and distribution networks.

- Adoption of distributed power sources for frequency control/support.

- The related projection information/time series/technologies for the evolution of the Cyprus grid system for the year 2050.

The work in this paper can be extended further so that the smart solutions developed can be selectively automated and related to the hierarchical control of the interconnected grid to form the operational regime of low inertia systems. New methodologies, offline or online, must be developed to improve the estimation of the appropriate controllers' parametrization for securing the healthy and responsive operation of the power grid in all emerging conditions.

Author Contributions: Conceptualization, M.P.; simulations, M.P.; methodology, M.P. and C.N.P. and V.E.; software, M.P.; development of grid under test, M.P. and C.N.P. and V.E.; implementation and evaluation of results, M.P. and C.N.P. and V.E.; validation, M.P. and C.N.P. and V.E.; design/development of optimization method, M.P; literature review, C.N.P.; problem formulation, M.P., C.N.P. and V.E.; research motivation/innovation, M.P., C.N.P. and V.E.; formal analysis, M.P., C.N.P. and V.E.; investigation, M.P., C.N.P. and V.E.; resources, M.P., C.N.P. and V.E.; data curation, M.P.; writing — original draft preparation, M.P., C.N.P. and V.E.; writing—review and editing, M.P., C.N.P. and V.E.; visualization, M.P.; supervision, M.P., C.N.P. and V.E.; project administration, C.N.P. and V.E.; funding acquisition, C.N.P. and V.E.; All authors have read and agreed to the published version of the manuscript.

Funding: This research was funded by European Union's Horizon 2020 Research and Innovation Programme grant number 773708. 
Data Availability Statement: The dataset on which this paper is based is too large to be retained or publicly archived with available resources. Documentation and methods are described in detail in the context of the paper to help reproducing the outcomes/results. On the other, the grid model cannot be shared publicly due to confidentiality agreements with Electricity Authority of Cyprus. at https:/ / www.mdpi.com/ethics, accessed on 8 March 2021.

Acknowledgments: The project INTERPLAN has received funding from the European Union's Horizon 2020 Research and Innovation Programme under Grant Agreement No. 773708.

Conflicts of Interest: The authors declare no conflict of interest.

\section{References}

1. Winter, W.; Elkington, K.; Bareux, G.; Kostevc, J. Pushing the Limits: Europe's New Grid: Innovative Tools to Combat Transmission Bottlenecks and Reduced Inertia. IEEE Power Energy Mag. 2015, 13, 60-74. [CrossRef]

2. Holttinen, H.; Tuohy, A.; Milligan, M.; Lannoye, E.; Silva, V.; Müller, S.; Sö, L. The Flexibility Workout: Managing Variable Resources and Assessing the Need for Power System Modification. IEEE Power Energy Mag. 2013, 11, 53-62. [CrossRef]

3. Thies, H.H.; Schneider, M.; Zdrallek, M.; Schmiesing, J. Future structure of rural medium-voltage grids for sustainable energy supply. In Proceedings of the CIRED 2012 Workshop: Integration of Renewables into the Distribution Grid, Lisbon, Portugal, 29-30 May 2012; pp. 1-4.

4. Pouresmaeil, E.; Mehrasa, M.; Godina, R.; Vechiu, I.; Rodríguez, R.L.; Catalão, J.P.S. Double synchronous controller for integration of large-scale renewable energy sources into a low-inertia power grid. In Proceedings of the 2017 IEEE PES Innovative Smart Grid Technologies Conference Europe (ISGT-Europe), Torino, Italy, 26-29 September 2017; pp. 1-6.

5. Keyhani, A.; Chatterjee, A. Automatic Generation Control Structure for Smart Power Grids. IEEE Trans. Smart Grid 2012, 3 , 1310-1316. [CrossRef]

6. Zhang, Y.; Rahbari-Asr, N.; Duan, J.; Chow, M. Day-Ahead Smart Grid Cooperative Distributed Energy Scheduling With Renewable and Storage Integration. IEEE Trans. Sustain. Energy 2016, 7, 1739-1748. [CrossRef]

7. Patsalides, M.; Papadimitriou, C.N.; Efthymiou, V.; Ciavarella, R.; Di Somma, M.; Wakszyńska, A.; Kosmecki, M.; Graditi, G.; Valenti, M. Frequency Stability Evaluation in Low Inertia Systems Utilizing Smart Hierarchical Controllers. Energies 2020, 13, 3506. [CrossRef]

8. Toma, L.; Sanduleac, M.; Baltac, S.A.; Arrigo, F.; Mazza, A.; Bompard, E.; Musa, A.; Monti, A. On the virtual inertia provision by BESS in low inertia power systems. In Proceedings of the 2018 IEEE International Energy Conference (ENERGYCON), Limassol, Cyprus, 3-7 June 2018; pp. 1-6. [CrossRef]

9. Morren, J.; de Haan, S.W.H.; Kling, W.L.; Ferreira, J.A. Wind turbines emulating inertia and supporting primary frequency control. IEEE Trans. Power Syst. 2006, 21, 433-434. [CrossRef]

10. Serban, I.; Teodorescu, R.; Marinescu, C. Energy storage systems impact on the short-term frequency stability of distributed autonomous microgrids, an analysis using aggregate models. IET Renew. Power Gener. 2013, 7, 531-539. [CrossRef]

11. Papadimitriou, C.N.; Vovos, N.A. Transient Response Improvement of Microgrids Exploiting the Inertia of a Doubly-Fed Induction Generator (DFIG). Energies 2010, 3, 1049-1066. [CrossRef]

12. Knap, V.; Chaudhary, S.K.; Stroe, D.-I.; Swierczynski, M.J.; Craciun, B.-I.; Teodorescu, R. Sizing of an Energy Storage System for Grid Inertial Response and Primary Frequency Reserve. IEEE Trans. Power Syst. 2016, 31, 3447-3456. [CrossRef]

13. Amraee, T.; Darebaghi, M.G.; Soroudi, A.; Keane, A. Probabilistic under frequency load shedding considering RoCoF relays of distributed generators. IEEE Trans. Power Syst. 2018, 33, 3587-3598. [CrossRef]

14. Li, C.; Wu, Y.; Sun, Y.; Zhang, H.; Liu, Y.; Liu, Y.; Terzija, V. Continuous Under-Frequency Load Shedding Scheme for Power System Adaptive Frequency Control. IEEE Trans. Power Syst. 2020, 35, 950-961. [CrossRef]

15. Annamraju, A.; Nandiraju, S. Load Frequency Control of an Autonomous Microgrid Using Robust Fuzzy PI Controller. In Proceedings of the 2019 8th International Conference on Power Systems (ICPS), Jaipur, India, 20-22 December 2019; pp. 1-6. [CrossRef]

16. Das, C.; Roy, A.K.; Sinha, N. GA based frequency controller for solar thermal-diesel-wind hybrid energy generation/energy storage system. Int. J. Electr. Power Energy Syst. 2012, 43, 262-279. [CrossRef]

17. Pandey, S.K.; Mohanty, S.R.; Kishor, N.; Catalão, J.P.S. Frequency regulation in hybrid power systems using particle swarm optimization and linear matrix inequalities based robust controller design. Int. J. Electr. Power Energy Syst. 2014, 63, 887-900. [CrossRef]

18. El-Fergany, A.A.; El-Hameed, M.A. Efficient frequency controllers for autonomous two-area hybrid microgrid system using social-spider optimizer. IET Gener. Transm. Distrib. 2017, 11, 637-648. [CrossRef]

19. Annamraju, A.; Nandiraju, S. Frequency Control in an Autonomous Two-area Hybrid Microgrid using Grasshopper Optimization based Robust PID Controller. In Proceedings of the 8th IEEE India International Conference on Power Electronics (IICPE), Jaipur, India, 13-15 December 2018; pp. 1-6.

20. Shaker, H.K.; Zoghby, H.E.; Bahgat, M.E.; Abdel-Ghany, A.M. Advanced Control Techniques for an Interconnected Multi Area Power System for Load Frequency Control. In Proceedings of the 2019 21st International Middle East Power Systems Conference (MEPCON), Cairo, Egypt, 17-19 December 2019; pp. 710-715. [CrossRef] 
21. Liu, Y.; You, S.; Liu, Y. Study of Wind and PV Frequency Control in U.S. Power Grids-EI and TI Case Studies. IEEE Power Energy Technol. Syst. J. 2017, 4, 1-9. [CrossRef]

22. Ochoa, D.; Martinez, S. Fast-Frequency Response Provided by DFIG-Wind Turbines and its Impact on the Grid. IEEE Trans. Power Syst. 2017, 32, 4002-4011. [CrossRef]

23. Thorbergsson, E.; Knap, V.; Swierczynski, M.; Stroe, D.; Teodorescu, R. Primary Frequency Regulation with Li-Ion Battery Based Energy Storage System-Evaluation and Comparison of Different Control Strategies. Intelec 2013. In Proceedings of the 35th International Telecommunications Energy Conference, Smart Power and Efficiency, Hamburg, Germany, 13-17 October 2013; pp. 1-6.

24. Nguyen, H.T.; Yang, G.; Nielsen, A.H.; Jensen, P.H. Combination of Synchronous Condenser and Synthetic Inertia for Frequency Stability Enhancement in Low-Inertia Systems. IEEE Trans. Sustain. Energy 2019, 10, 997-1005. [CrossRef]

25. Rikos, E.; Cabiati, M.; Tornelli, C. Adaptive frequency containment and balance restoration controls in a distribution network. In Proceedings of the 2017 IEEE PES Innovative Smart Grid Technologies Conference Europe (ISGT-Europe), Torino, Italy, 26-29 September 2017; pp. 1-6.

26. Syed, M.H.; Guillo-Sansano, E.; Blair, S.M.; Roscoe, A.J.; Burt, G.M. A Novel Decentralized Responsibilizing Primary Frequency Control. IEEE Trans. Power Syst. 2018, 33, 3199-3201. [CrossRef]

27. Martini, L.; Brunner, H.; Rodriguez, E.; Caerts, C.; Strasser, T.I.; Burt, G.M. Grid of the future and the need for a decentralised control architecture: The web-of-cells concept. Cired Open Access Proc. J. 2017, 2017, 1162-1166. [CrossRef]

28. Rakhshani, E.; Gusain, D.; Sewdien, V.; Torres, J.L.R.; Van Der Meijden, M.A. A Key Performance Indicator to Assess the Frequency Stability of Wind Generation Dominated Power System. IEEE Access 2019, 7, 130957-130969. [CrossRef]

29. Policy 1: Load-frequency control and performance, ENTSO-E, Continental Eur. Oper. Handbook. Tech. Rep. 2018. Available online: https://www.entsoe.eu/_leadmin/user_upload/_library/publications/entsoe/Operation_Handbook/Policy_1_nal. pdf (accessed on 10 September 2020).

30. RG-CE System Protection \& Dynamics Sub Group (REE, Terna, TransnetBW, 50Hertz Transmission, RTE, Swissgrid and Energinet. dk). Frequency Stability Evaluation Criteria for the Synchronous Zone of Continental Europe; ENTSO-E: Brussels, Belgium, 2016.

31. Bao, W.; Zhang, X.; Zhao, L. Parameter estimation method based on parameter function surface. Sci. China Technol. Sci. 2013, 56, 1485-1498. [CrossRef]

32. Pham, N.; Wilamowski, B.M. Improved Nelder Mead's Simplex Method and Applications. J. Comput. 2011, 3, 55-63.

33. Lagarias, J.C.; Reeds, J.a.; Wright, M.H.; Wright, P.E. Convergence Properties of the Nelder-Mead Simplex Method in Low Dimensions. Siam J. Optim. 1998, 9, 112-147. [CrossRef]

34. Patsalides, M.; Efthymiou, V.; Stavrou, A.; Georghiou, G.E. A generic transient PV system model for power quality studies. Renew. Energy 2016, 89, 526-542. [CrossRef] 